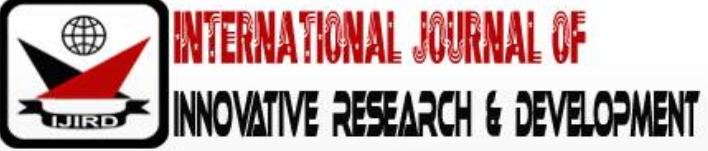

ISSN 2278 - 0211 (Online)

\section{Regional Integration in West Africa: The Mano River Union in Focus}

\author{
Dr. Musa Ibori \\ Lecturer, Department of Political Science and International Relations, \\ University of Abuja, Nigeria \\ Adie Edward Idagu \\ Ph.D. Student, Department of Political Science and International Relations, \\ University of Abuja, Nigeria \\ Nwokedi Lawretta Obiageli \\ Ph.D. Student, Department of Political science and International Relations, \\ University of Abuja, Nigeria
}

\begin{abstract}
:
The paper explored regional integration process among the Mano River Union (MRU) member countries using the Neofunctionalist approach to region integration. It adopted the qualitative research method and obtained its data from the secondary sources. These include textbooks, articles, journals, dissertations, news papers and magazines as well as internet materials. The analysis of the study was based on content analysis. The findings indicated that the Mano River Union has recorded some degree of achievements among its members. These achievements include the promotion of intra-trade and other related activities among member states; provision of infrastructure like roads, bridges; capacity development across member states etcetera. The Union also has faced challenges ranging from insecurity, huge indebtedness, outbreak of diseases such as ebola virus, lack of befitting accommodation for the Union Secretariat, general poverty among member states etcetera. On the theoretical perspective, the findings showed that some of the tenets of neo-functionalism found relevance in the formation and functions of the Mano River Union. Thus, the themes of limited objective, spill over, the role of non-state actors and the importance of State actors in the integration process all correspond with the formation and operations of the Mano River Union. Recommendations among others include: The member states should work hard to settle all the current debts and avoid incurring new ones; the joint committee established following the expanded mandate of the Union should be supported with all necessary requirements to function well. Intelligent and information sharing and gathering among the member states should be promoted; The rates of intra-trade among members appears good, effort should be made to encourage more trade in different items among members states; More strategies be adopted in partnership with other countries and international organizations to enhance security, peace and stability in the region etcetera.,
\end{abstract}

Keywords: Regional integration, Mano river union, neo-functionalism, ebola virus

\section{Introduction}

The field of international relations has increasingly become agog with issues bordering on Regional integration today because nation states have come to realize the importance of cooperation to facilitate the achievement of common aspirations. It has been proven that when states cooperate or integrate they are bound to reap benefits in economic, political and social spheres for their members. Thus, in the economic milieu, countries who integrate can achieve economies of scale, optimally allocate scarce resources and accelerate economic growth or increase trade. Also politically, regional integration can boost a country military prowess, augment political status and wade-off aggression etcetera. (Ibori,2019). These benefits have therefore influenced the creation of several regional organizations virtually in all regions of the world. The same applies to the Mano River Union (MRU) whose establishment according to the founding members was borne out of the need to "accelerate the economic growth, social progress and cultural advancement of our two countries... by active collaboration and mutual assistance in matter of common interest in economic, social, technical, scientific and administrative fields" (United Nations, 1974:266). The desire to have this Union in place started way back in 1967 but it was on October 3, 1973 that it became a reality following the signing of the "Malema Declaration" by the Presidents of Sierra Leone and Liberia (Boye-Thompson, 2017). Since then, the Union in the words of Wathi (2017) "maintains the initiation of dialogue at all levels between states for the purpose of achieving great unity and solidarity, and promoting goodwill, neighbouring cooperation and peaceful coexistence amongst its people, promoting peace, security, democratic principles and popular participation of citizens in the pursuit of good governance".

The study shall therefore, analyze the Mano River Union as one formidable region organization within the West Africa Sub-region through the lens of Neo-functionalism. The purpose of doing this is to see how this framework can 
possibly be used to explain the formation and functions of the Mano River Union which was established ab initio to promote economic cooperation with respect to customs union among member states but has now extended cooperation to other spheres, including security that was hitherto not included in the original goal. In so doing, the Union has, in a way, fulfilled one of the tenets of neo-functionalism- the spill-over effect. The paper is divided into sections as follows: the Introduction, Conceptual Clarifications, Theoretical Perspective, Historical Background to the Formation of Mano River Union, Objectives of the Mano River Union, Membership, Organs, Achievements and Challenges of the Mano River Union, conclusion and recommendations.

\section{Conceptual Clarifications}

Regional integration is a concept that almost everybody in the disciplines of economic, political science, history and international relations is familiar with but its definition according to Bolanōs (2016) "remains controversial". Notwithstanding, this section has carefully selected some definitions to guide us in understanding the concept of regional integration. According to Sessay cited in Udoh (2015:2) regional integration "refers to the various forms and contexts of economic integration arrangements, including common markets, free trade areas and harmonization of policies, prevailing or proposed at both the continental, that is African Economic Community (AEC) and regional such as ECOWAS, South Africa Development Commission (SADC) levels among others". Niekerk (2005:4) defines regional integration along three dimensions of geographic scope, which illustrates the number of countries involved in the arrangement; the substantial coverage or width that is sector or activity coverage, including trade labour mobility, macro-policies-sector policies etcetera and; the depth of interaction to measure the degree of sovereignty a country is ready to surrender that is from single condition or cooperation to deep integration. Van Ginkel and van Langenhove (2003) see regional integration as "a process by which states within a particular region increase their level interaction with regard to economic, security, political or social and cultural issues". This definition stresses the multidimensional characteristics of regional integration and thus, shares similarity with the Economic Community for Latin America and the Caribbean (ECLAC, 2014) which considers the concept of regional integration as a "multi-dimensional process which may take the form of coordination, cooperation, convergence and deep integration initiatives and whose scope extends not only to economic and social issues but to political, social, cultural and environment ones as well."

What is important regarding these definitions is that regional integration entails the coming together of different countries to promote goals, values aspiration, etcetera they all cherished be it in political or economic spheres, but it usually begins with the economic front and then extends to other areas of cooperation.

\subsection{Mano River Union: The Theoretical Perspective}

The theoretical approach adopted in this study is Neo-functionalism. Neo-functionalism is a regional integration theory that revived David Mitrany's functionalism early propounded in the 1940s. The theory was spearheaded by Ernst Haas through his 1958 study TheUniting of Europe and later got popularized by Leon Lindberg where he used its major tenet to study the early years of European Economic Community (Laursen, 2008:3). Neo-functionalism shares some basic assumptions with functionalism as it stresses on the mechanism of technocrat decision making, incremental change and learning process (Niemann and Schmitter, 2009:1). The theory received a lot of accolades in the 1960s because it was at that time the European integration process was high but by 1970s it started losing relevance owing to internal politics in Europe. However in the 1980s there was a "comeback" of the neo-functionalism as attempts were made to revise its former idea (Niemann and Schmitter, 2009:1). One important distinguishing feature of this theory is the concept of spill over which explains how regional integration moves from one sector to another. Thus,

In order to fulfill and satisfy one goal of integration it is necessary to take actions in another area, which then set other action in motion. Within political spill over, it meant that when one sector integrated, the interest groups usually lobbying on national level then switch to the new integrated supranational agency, which then encourages other national groups to pressure their national access points to integrate as well (Kleinschmitcited by Adie, 2017:596).

Looking at the formation and function of the Mano River Union through the Neo-functionalist lens, one sees some linkages between the two. For instance, neo-functionalism emphasizes the relevance of early institutionalization of limited cooperation and expects its later expansion (Gehring, 1996:229). This is exactly what happened in the Mano River Union as the Malema Declaration of 1973 only centred on limited cooperation in the area of custom Union among member state(Wathi, 2017).

Neo-functionalism draws attention to the relevance of sub-national or non-states actors in the integration process (Gehring, 1996: 229). In the Mano River Union, some non-states actors are also involved in promoting integration in the region. For instance, there is a Mano River Union Youth Parliament (MRUP), which is a sub-regional network of young peace builders, students, Journalists, development experts and human rights activists from Guinea, Liberia and Sierra Leone advocating peace, human rights and development of the youth in their communities (MRUYP, 2003). There is also the Mano River Women's Peace Network (MARWOPNET) as non state actor promoting cooperation and integration in member countries.

Neo-functionalists argued that even though non-state actors like civil society organizations etcetera, drive integration, states remain relevant actors in the integration process (Schmitter, 2002). The same applies in the Mano River Union as the four member countries are still very much relevant in the integration of the sub-region.

The theory talks about increased cooperation or interdependence between member states in one functional issue area can lead to interdependence in another. As noted early the formation of the Mano River Union was based on the desire for cooperation on economic aspect-customs union but was later expanded to cover other aspect including security. This is 
why the Union has common collaboration by defence Ministers of member states to share security information to prevent regional threat (User, 2016) for effective and overall integration of the region

Another feature of neo-functionalism is the idea of "political integration which is linked to the 'emergence of a new political community superimposed over the pre-existing ones', and based on the anticipated shift of the loyalties of elite from national to the supranational" (Gehring, 1996:229). Concerning this point, the Mano River Union is making effort towards this direction. For instance in 2016, the Union announced its plan to establish the "Mano River Union Parliament where lawmakers from the four countries will look at the legislative deliberations on major issues in their respective countries and work together on regional matters that require legislative enactment"(Usher, 2016).

\subsection{Historical Background to Formation of Mano River Union}

Historically, the establishment of Mano River Union was premised on the desire by the two pioneer member countries of Liberia and Sierra Leone to "forge some kind of cooperation to facilitate the economic development of their respective countries" (Al-hassan, 2012) right from 1967 (Couteh, 1975:103). In furtherance of this long-held desire, the leaders of the two countries met in 1971 and issued a joint statement on mutual economic cooperation, and thereafter in 1972 requested the United Nations Development Programme(UNDP) "to mount a joint UNTAD/ UNIDO/ FAO mission to examine the possibilities of cooperation between the two countries" (Cole, 2000:10). Based on the mission's report, a joint Ministerial Committee gave recommendations that paved way for the signing of Declaration of the Mano River Union by Presidents Williams R. Tolbert of Liberia and Siaka P. Stevens of Sierra Leone on 3rd October, 1973 at Pujelum District in Southern Province of Liberia (Intergiagnostix, 2015; Cole, 2000:10-11, Couteh, 1975).

The Union derived its name from the Mano River which begins in Guinea highlands and flows through Sierra Leone, Liberia and joins the Atlantic Ocean (Poole and Mohammed, 2013:11). The River, in the words of Rogers (2015) is "like an umbilical cord that weaves through them [member states]" thus causing Guinea to seek membership in 1980 (Nelson and Bassene, 2003:3) and Cote D'Ivoire in 2008 (Association of European Border Regions (AEBR, 2012). The Declaration was meant to achieve custom union in two phases. The first phase which was planned for January 1, 1977 included: The liberalization of mutual trade in goods of local origin, through the elimination of tariff and barriers to such trade; The harmonization of rates of import duties and other fiscal incentives applicable to goods of local origin, in order to ensure for trading conditions and a harmonized productive policy for local producers and; Supporting measures necessary to the cooperation in the production of agricultural and manufactured products of local origin (United Nations, 1974:266). But due to insecurity in member countries of Liberia and Sierra Leone, the Union couldn't meet its planned economic cooperation but further effort saw the reactivation of the Union at the Summit of the Heads of State of Mano River Union from Liberia, Sierra Leone and Guinea on 20th May, 2004 (AEBR, 2012).

It is important to note that the original content of the Union's Declaration has passed through several modifications with different protocols being added to meet the pressing demands of the member states. Thus, at the moment there are a total of 16 protocols governing the institutions as well as operations of the Union (Interdiagnostix, 2015?)

\subsection{Objectives of Mano River Union}

The MRU has two major objectives as follows:

- To expand trade; by the elimination all barriers to mutual trade; by cooperation in the expansion of international trade; by the creation of conditions favourable to an expansion of mutual productive capacity, including the progressive development of a common productive and cooperation and in the creation of new productive capacity.

- Secure a fair distribution of benefit from economic cooperation (United Nations, 1974:266).

\subsection{Membership of Mano River Union}

Membership of Mano River Union according to its $5^{\text {th }}$ protocol is open to other West African countries to be part of the union. This explains why Guinea and Cote D' Ivoire became members of the Union after the initial Declaration in 1973. Currently there are four member countries of the Union. These include the two founding members: Liberia (1973) and Sierra Leone (1973), Guinea (1980) and Cote d' Ivoire (2008) (Nelson and Bassene, 2003:3; Iza, 2018:10). The table below shows the estimated population, areasand Gross Domestic Product (GDP) of the Union Member countries.

\begin{tabular}{|c|c|c|c|c|}
\hline Country & Population (Million) & Area (Sqkm) & GDP(Million USD) & $\begin{array}{c}\text { GDP Per Capita } \\
\text { (USD) }\end{array}$ \\
\hline Cote d' Ivoire & 20.2 & 322,463 & 24,074 & 1,195 \\
\hline Guinea & 10.2 & 245,857 & 5,120 & 502 \\
\hline Liberia & 4.1 & 111,369 & 1,545 & 374 \\
\hline Sierra Leone & 6.1 & 71,740 & 2,243 & 374 \\
\hline Mano River Union & 40.5 & 750,429 & 32,983 & 815 \\
\hline Tanzania (for Comparison) & 37.8 & 945,090 & 27,365 & 723 \\
\hline
\end{tabular}

Table 1 Population Estimates of the Member States of Mano River Union (2011)

Source: World Bank Cited In Interdiagnostix (2015)Www.Interdiagnostix.Com/ Car-Rta/ Mano-River-Union 


\subsection{Organs of Mano River Union}

The Mano River Union has four basic organs that coordinate and implement all its programmes and policies. These include the Summit of the Heads of State and Government of the member countries; the Ministerial Council; the Technical Commissions and the Secretariat. Details of these organs are discussed below.

\subsection{The Summit}

The Summit comprises the Heads of State and Government of member countries who meet once or twice as the case may be in a year to discuss important issues that are crucial to the member states. The body is responsible for the admission of new members into the Union, approval of budgetary provision etcetera.

\subsection{The Ministerial Council}

This composed of Ministers from member states whose function include planning, development, economic cooperation, finance, education, trade industry, agriculture, transportation, communication, energy natural resources and works(Wathi, 2017; Interdiagnostix, 2015). Members of the organ meet annually and take decisions by consensus. It also makes recommendations to the summit of the union and other member states for certain actions to be taken. And gives directives to the Secretariat and other subordinate institutions (Wathi, 2017)

\subsection{The Technical Commissions}

Another organ of the Mano River Union is the Technical Commission. This organ has members that are experts and professionals in their various fields of endeavours. They are expected to meet annually but can also meet at extraordinary times. The major functions are the examination of issues relating to their respective fields on their initiative as directed by the ministerial councilor or as requested by the Secretary General (Wathi, 2017). According to the above cited source, the organ was proposed to bear responsibilities in their respective sectors including trade and industries; agriculture, forestry and fisheries; transport and communications; education, training and research; finance and administration; energy and natural resources; peace and security. According to Interdiagnostix, (2015) these are the seven technical commissions that exist now in the Unions

\subsection{The Secretariat}

The secretariat is headed by a Secretary General with three other supporting staff as deputies. The office performs the following functions: prepares strategic plans for the Union, oversees the formulation of projects and program in support of the plan as well as their implementation, monitoring, evaluation, and report preparation, plan for and facilitate the holding of meeting of the institution of the union, approves projects and program in support of the objectives of the Union, represents the Union at various fora geared towards the political, social and economic development of the sub region, and mobilizes resources in support of projects and programs for the Union (Wathi, 2017). Cole (2000:12) has hinted that the secretariat has under taken several priority measures in achieving the objectives of the Union. These he listed to include: abolition of all obstacles to free movement of persons, goods, services and capital among member states; harmonization of policies in the agricultural, animal production, fishery, forestry, implementation of sub-regional infrastructure development programme in transportation, communication and power generation; promotion of harmonious and equitable relations among member states; formulation and execution of joint investment policies; adoption and implementation of customs tariff as well as the institution of appropriate compensation arrangement for losses incurred as a result of the common tariff policy; harmonization of the monetary policy; evaluation of common research, training health, sports and cultural policies; coordination of member states foreign policies, especially where there have economic implications undertake any other action in furtherance of the objectives of the union. The secretariat according to FOI (2007: 34) also "oversees the day-to-day implementation of the decisions made by the forum".

\section{Achievements of Mano River Union}

The Mano River Union has attained some degree of achievements since its formation in 1973. These include trade and customs; industries; agriculture; transportation and energy as well as trainings. For instance, intra-trade value in 1983 by Sierra Leone to Liberia was estimated at 722,519 US Dollars, while that of Liberia to Sierra Leone was 54,328 US dollars and that of Liberia to guinea was calculated at 75,000 US Dollars (Al-Hassan, 2012).

Also Cole (2000:11) reported that in 1977 the union introduced a common external tariff while locally produced goods became liberalized in May 1981. And also that "the objectives of customs union had been achieved and further plans had been formulated for the flagging of the Union export credit guarantee scheme". In the area of agriculture, the author maintained that the MRU has cooperation covering research and production, forestry, fisheries and livestock, noting that the union has achieved successes in the establishment of agric orientated projects such as the development of Mano River Basin, Mixed farming and the introduction of mini-mills for the processing of agricultural products as well as mini-palm oil mills in guinea and Sierra Leone (Cole, 2000:11).

Similarly, the union has been able to launch the Mano river bridge between the two member countries of sierra Leone and Liberal in 1977 and by 1988 some major parts linking the capitals of the two countries were completed (Cole, 2000:11).

In addition, the Union has fared well in the area of training as its members have benefited severally from training programmes and the creation of institutions. Some example are "the Union Forestry training institute, the Telecommunication and Postal Training institute, the marine training institute, the Customs Excise and trade Statistic 
Programmed, the Scholarship and Fellowship programme and the curriculum planning, industrial Material Production and Book Development Project (Cole, 2000:12).

\subsection{Promotion of Freedom of Expression}

The Mano River Union has also been commended for promoting freedom of the press. This became public when in 2012 the Union celebrated the World Press Freedom Day with focus on such themes as Journalism; Peace and democracy: How to use media freedom to improve the democratic development of the member country; role of the media in transitional environment and, the fostering accountability (UNESCO, 2012)

\subsection{Commitment towards Eradication of Neglected Tropical Diseases (Ntds)}

Another achievement by the Union is the commitment towards the eradication of NTDs among member countries. Thus at the $9^{\text {th }}$ Annual Conference of the Union held in Monrovia in 2016, member states called for the implementation of their planned activities to achieve the World Health Organization (WHO) target roadmap by 20202. Other keys takeaway include the launch of the countdown programme intended to support intervention to eradicate NTDs; appointment of some persons as NTDs Ambassador; and the integration of NTDs Surveillance into the national surveillance system(WHO, 2016) Other achievements include the promotion of dialogue on election, youth violence and conflict prevention among member states (Bah,2014)

\subsection{Challenges of Mano River Union}

The Union has faced a lot of challenges that have affected its performances. To begin with its authority is often undermined by the Economic Community of West African States (ECOWAS). As noted by FOI (2007:34) "MRU [Mano River Union] functions under the umbrella of ECOWAS. All legislative matters proposed by MRU are to be coordinated with ECOWAS. This is of course complicated, as ECOWAS may 'dictate' what can be allowed and what cannot".

Another set of challenges faced by the Union is about poor infrastructure, unnecessary harassment and extortion of traders on major roads. Al-Hassan (2012) spoke on this and many more:

Traders plying the Freetown-Monrovia and Freetown-Conakry were subjected to harassment at numerous check points along the routes, the freight charges are high and certain sections of the high ways are impassable during rainy season. There was a massive smuggling of goods from non-member countries that are similar to and compete with products of local origin in the Union markets. The production capacities are very low. And there is no regional industrial bank or fund to facilitate the mobilization of financial resources within the member states

\subsection{Conflicts / Wars}

As seen in Table 2 below, members of the Union have witnessed incessant wars within their borders. For instance, between 1989 and 1996 as well as 1999 and 2003, Liberia, a key founding member was engaged in civil wars that almost ruined the country. Also from 1991 to 2002 Sierra Leone experienced its own too (Iza, 2018:9). This also included the election violence that engulfed the Ivorian society in 2010 following the declaration of Mr Oauttara as winner by the Independence Electoral Commission (IEC) after the November 28, 2010 Presidential elections. Later the constitutional Court declared Mr Gbagbo winner of the same election leading to violence in the country with numerous impacts across member states (Ettang, Main and Razia 2011:5). All these have affected the overall performances of the Union as no meaningful development can take place in the midst of conflict/ wars as witnessed in the region

\begin{tabular}{|c|c|c|c|c|}
\hline Name of Conflict & Country & Years & Nature of Conflict & Fatalities(Estimates) \\
\hline First Liberian Civil War & Liberia & $1989-1996$ & Civil War & $100,000-220,000$ \\
\hline Sierra Leone Civil War & Sierra Leone & $1991-2002$ & Civil War & $50,000-300,000$ \\
\hline Second Liberian Civil War & Liberia & $1999-2003$ & Civil War & $150,000-300,000$ \\
\hline First Ivorian Civil War & Côte d'Ivoire & $2002-2007$ & Civil War & 3,000 \\
\hline Second Ivorian Civil War & Côte d'Ivoire & $2010-2011$ & Civil War & 3,000 \\
\hline
\end{tabular}

Table 2: Wars in Côte d'Ivoire, Liberia and Sierra Leone

Source: Marc Et Al Cited in Allouche, Benson and Cormarc (2016:5)

\subsection{Excessive Debts by Member States}

Besides the challenges already discussed, the Union members are also faced with huge public debt crisis amounting to US\$8billion. This has contributed in slowing down the pace of integration among the Union members. From Table 3 below, as at 2014 the public debt of Guinea was \$6.5 billion; Liberia \$815million and Sierra Leone \$1.49billion. Their individual external commitments are also captured as Guinea has \$1.6billion, Liberia 531.42million and Sierra Leone 1.1billion. 


\begin{tabular}{|c|c|c|c|}
\hline & Public Debt & External Commitment & \\
\hline Guinea & US\$6.5billion & US\$1.6 billion & $98 \%$ \\
\hline Liberia & US\$815million & US\$531.42million & $40 \%$ \\
\hline Sierra Leone & US\$1.49billion & US\$1.1billion & $33 \%$ \\
\hline Total & US\$8.7billion & US\$3.16billion & $64 \%$ \\
\hline
\end{tabular}

Table 3: The Size of Public Debt of Guinea, Liberia and Sierra Leone in 2014

Source: Mano River Union Post-Ebola Socio-Economic Recovery Programme (2015:19)

\subsection{Ebola Virus}

The outbreak of Ebola Virus in some member countries of the Union has far reaching devastating effects on the integration process in the region. As noted in a joint statement by the three Presidents of the affected states, the total number of deaths from the virus "stood at 11,000 out of 27,000 confirmed cases; more than 20,000 children have lost one or both parents; and at least 3,000 women have been widowed. Our economies went into free-fall, resulting in projected real GDP growth rates in 2014 declining from 4.5 percent to 1.1 percent in Guinea, 11.3 percent to 7.1 percent in Sierra Leone and 5.9 percent to 0.7 percent in Liberia" (Conde, Sirleaf and Koroma, 2015:1). Koroma (2015:3) further maintains that "Ebola brought about overwhelming challenges in almost every aspect of life in Sierra Leone, Liberia and guinea. Our health systems almost collapsed;...farms were neglected; markets abandoned; trade and travel contracted; fiscal balances weakened; revenue decreased; and expenditure shut up to combat the disease". The most disturbing thing as noted by President Koroma is ..."the enormous health, fiscal, education, and livelihood challenges brought about by the virus are still upon us"

\subsection{Lack of Befitting Accommodation for the Union Secretariat}

From the account of Cole (2000:12) the Secretariat of the MRU is still located on a rented apartment known as "Delco House" belonging to a mining company. If after over 50 years of existence the Union cannot boast of a personal befitting office accommodation for its staff then it calls for concern on how it would be able to execute its function effectively.

\section{Conclusion}

The paper made an attempt to analyze regional integration under the auspices of the Mano River Union using the neo-functionalist theory as propounded by Ernst Haas and popularized by Leon Lindbery. The general overview of the formation, historical background, objectives, organs, membership, achievements and the challenges of the Mano River Union were given adequate treatment in the study. Accordingly, the paper noted that the Union has registered some degree of successes even though there are many challenges still confronting the Union. These successes or achievements include the promotion of intra-trade and other related activities among member states; provision of infrastructure like roads, bridges; capacity development across member states etcetera. The Union also has faced challenges ranging from insecurity, huge indebtedness, outbreak of ebola virus, lack of befitting accommodation for the Union Secretariat, general poverty among member states, etcetera. Despite these challenges the paper believed that there are good chances (prospects) for the union to enhance integration among its member states. This can be gleaned from the joint efforts to combat ebola virus, the building of bridges linking member states, the ongoing consultation to establish MRU parliament as well as other existing arrangements that promote integration within the sub-region by member states.

On the second part which dwelled on the theoretical perspective, the paper noted that some of the tenets of neofunctionalism found relevance in the formation and function of the Mano River Union. For instance, the themes of limited objective, spill over, the role of non-state actors and the importance of State actors in the integration process- all correspond with the formation and operation of the Mano River Union. Though it has been argued that "no theory of regional integration has been misunderstood, caricatured, pilloried, proven wrong and rejected as often as neofunctionalism" (Shemitter,2002:1), the use of this framework has proved useful and can be applied in the study of other regional integration arrangements in spite of its limitations.

\section{Recommendations}

- The member states of MRU should ensure they settle all the current debts and avoid incurring new ones.

- The joint committee established following the expanded mandate of the Union should be supported with all necessary requirements to function well. Intelligence and information gathering and sharing among member states should be promoted

- The rates of intra-trade among members appears good, effort should be made to encourage more trade in different items among members states

- More strategies be adopted in partnership with other countries and international organization to enhance security, peace and stability in the region

- Concrete development plans in infrastructure etcetera should be encouraged among member states to promote development and fight poverty.

- Massive awareness campaign on the prevention and treatment of dreaded diseases such as Ebola should be embarked on for the safety of the Union's citizens 


\section{References}

i. Adie, E. I. (2017). "An Overview of Central American Integration System" In: Sheriff, G. I. and Nwokedi, L.O. (Eds) Regional Integration in Africa and Beyond: From Theories, Political Alliance to Interdependence. Vol.II. Abuja Digit Link Xtra Limited.

ii. AEBR (2012)> "Opportunities for Cross Boeder Cooperationin West Africa: A Contribution to the Regional integration Process" R eference No 2010CE/ 60AT057. Germany:Association of European Border cooperation

iii. Al-Hassan S. A. (2012). "The Mano River Union" African Minarets. www.islam4africa.net/ en/ more.php?catld=\&artld=108

iv. Allouche, J., Benson, M. and Cormack, F. (2016). "Beyond Borders: The End of Mano River War (s)?”. England: Institute of Development Studies

v. Bah, S. (2014). "Man River union Dialogue on the Elections \& Conflict Prevention in Freetown" Trust Africa, 13 Jan, 2014

vi. Bolanōs, A. B. (2016). "A Step Further in the Theory of Regional Integration: A Look at the Unasur's Integration Strategy" Working Paper 1617-may, 2016

vii. Boye-thompson, T. (2017). "The Mano River Union: An Update”. The Patriotic Vanguard, 25 July, 2017

viii. Cole, M. O. (2000). United Nations Economic commissions for African Sub-regional Development Centre (SRDC/ WA) for West Africa. https:/ / repository.uneca.org/ bitstreams/ handle/ 10855/ 3276/ Bib26787.pdf?sequence=1

ix. Conde, A., Sirleaf, J. E. and Koroma, E. B. (Fwrd) (2015). "Mano River Union Advocacy Document: Ebola Recovery Strategies" being a Paper Presented at the International Conference on Ebola Recovery, 9-10 July, 2015, New York.

x. FOI (2007). "The Mano River Basin Area: Formal and Informal Security Providers in Liberia, Guinea and Sierra Leone". Stockholm: Swedish Defence Research Agency.

xi. Ginkel, V. H. and Langenhove, V. L (2003). "Introduction and Context” in Ginkel, V. H.; Court, J. and Langenhove, V. L. (Eds) Integrating Africa: Perspectives on Regional Integration and Development. UNU Press pp1-9

xii. Ibori, M. (2018). "Reasons for Regional Integration" Being a PG Class Lecture Delivered on 5th October, 2018, Parliamentary Building, University of Abuja, Gwagwalada.

xiii. Inter diagnostix (April 30, 2015). "The Mano River Union (MRU)” www.interdiagnostix.com/ car-rta/ mano-riverunion

xiv. Koroma, B. E. (2015). An Address by the His Excellency Dr. Ernest Bai Koroma President of the Republic of Sierra Leone on Behalf of the MRU nations at the African Union Ebola Recovery Conference Malabo Equatorial Guinea, July 21, 2015

xv. Laursen, F. (2008). "The Theory and Practice of Regional Integration". Jean Monnet/ Robert Schuman Paper Series Vol.8 No.3, February, 2008

xvi. Mano River Union Post -Ebola Socio-Economic Recovery Programmes (2015).https:/ / ebolaresponse.un.org/ sites/ default/ files/ mru Subregional_Socioeconomic_Strategy_090715_en.pdf

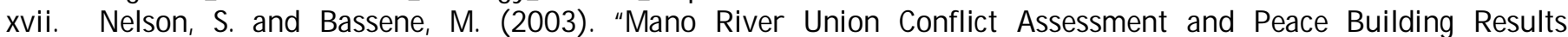
Framework" Creative Associates Int'l Inc in Collaboration with care the George Washington University Groundwork

xviii. Niekerk, L.K. (2005). "Regional Integration: Concepts, Advantages, Disadvantages and Lessons of Experience". Available at https:/ / sarpn.org/ documents/ d0001249/ P1416-RI-concepts My2005.pdf (Accessed on 9/ 10/ 2018)

xix. Poole, M. and Mohammed, J. A. (2013). "Border Community Security: Mano River Union Region". London: Conciliation Resources.

xx. UNESCO, (2012). "Mano River Union to Celebrate World Freedom Day" www.unesco.org/new/en/mediaservices/ single-view/ news/ mano river union to celebrate world press freedom day/

xxi. United Nations (1974). 'The Mano River Declaration: United Nations Treaty Series Vol.952,1-13608

xxii. User, S. (2016). "Mano River Union Countries to Establish Legislative Body" Front Page Africa, April 19, 2016

xxiii. Wathi, (2017). Presentation of the Mano River Union https:/ / www.wathi.org/ debat id/ organizations.regional/ wathinote-presentation-of-the-mano-river-union/

xxiv. WHO (2016). "Mano River Union countries Committed to Eradicate Neglected Tropical Disease" https:/ / afro.who.int/ news/ mano-river-union-countries-committed-eradicate-negleted-tropical-disease 